\title{
Circuit
}

Musiques contemporaines

\section{Hommage à Prévost. André Prévost et la danse : une rencontre fructueuse}

\section{Martine Époque}

Volume 12, numéro 1, 2001

Henri Pousseur : visages

URI : https://id.erudit.org/iderudit/902244ar

DOI : https://doi.org/10.7202/902244ar

Aller au sommaire du numéro

Éditeur(s)

Les Presses de l'Université de Montréal

ISSN

1183-1693 (imprimé)

1488-9692 (numérique)

Découvrir la revue

Citer ce document

Époque, M. (2001). Hommage à Prévost. André Prévost et la danse : une rencontre fructueuse. Circuit, 12(1), 101-102. https://doi.org/10.7202/902244ar d'utilisation que vous pouvez consulter en ligne.

https://apropos.erudit.org/fr/usagers/politique-dutilisation/ 


\section{Hommage à Prévost André Prévost ef la danse : une rencontre fructueuse}

Martine Époque

"En octobre 1968, Paul Lapointe, qui avait participé comme choriste à la création de Terre des hommes, œuvre gigantesque et superbe du compositeur André Prévost, donnée pour l'ouverture de l'Exposition universelle de Montréal en 1967, me présenta au maître. Cette rencontre se révéla majeure pour Nouvelle Aire, car André deviendrait un de ses spectateurs les plus assidus, un porte-parole fidèle, son défenseur acharné, son premier président à provenir de l'extérieur du Groupe, son unique président honoraire et, surtout, le compositeur dont le plus d'œuvres ont donné lieu à des chorégraphies à la compagnie'. "

Cette première rencontre fut la seule formelle que nous connûmes. En fait, dans son bureau à la Faculté de musique de l'Université de Montréal, impressionnée par le personnage, je devrais dire que les quelques premières minutes de notre entretien m'apparurent comme tel. Car avec la passion, la chaleur, la simplicité et l'intérêt dont ce compositeur humaniste, généreux et plein d'humour allait faire preuve, nous nous transformâmes ipso facto en vieux copains, puis, dans la foulée des jours et semaines suivants, en amis et collaborateurs indéfectibles.

Je garde aiguë dans ma mémoire l'image de Lise et André, assis en tailleur sur le plancher de la salle de danse, assistant concentrés et encourageants aux répétitions du Groupe en train de naître. C'était en novembre 1968. Nous ignorions alors que l'implication d'André dans la vie de Nouvelle Aire allait traverser toute son existence. Son apport fut majeur. C'est lui, par exemple, qui a permis au Groupe d'avoir accès à la salle de concert de l'École de musique Vincent-d'Indy pour y donner, en décembre 1969, son premier spectacle sous le nom de Nouvelle Aire. Marque du destin ? Cette même salle, trente et un ans plus tard et quelques jours avant sa mort, a vu la création de la dernière œuvre d'André et la longue ovation empreinte d'admiration, d'émotion et de respect que le public lui a consacrée.

C'est aussi André qui a aidé le Groupe à se produire à la Place des Arts dès 1971, en lui indiquant comment récupérer les salaires payés aux musiciens et chef d'orchestre qui ne jouaient pas pendant ses spectacles. C'est encore lui qui,
1. Époque. M. (1999) Les coulisses de la nouvelle danse au Québec, Le Groupe Nouvelle Aire en mémoires (1968-1982), Sainte-Foy, Les Presses de l'Université du Québec, p. 13. 
à la fin des années 70, intercédera auprès de Charles Lussier, directeur du Conseil des Arts du Canada, pour tenter de sauver la compagnie menacée de compression financière. C'est lui toujours qui a amené au Groupe d'autres compositeurs et musiciens avec qui des relations professionnelles et amicales se sont nouées et ont généré la création de plusieurs œuvres à la compagnie (Pierre Béluse, Micheline Coulombe-Saint-Marcouxt, Guy Lachapelle, Robert Leroux et Michel Longtin).

Figure marquante du Groupe à bien des points de vue, la contribution majeure d'André fut assurément celle de compositeur. Car, en nous ouvrant tout grand l'accès à ses œuvres et en nous accordant simultanément une liberté absolue qui témoignait de sa générosité et de son respect des autres, André a permis la création de huit chorégraphies dont plusieurs furent marquantes : Évanescence (1972) et Diallèle (1975), sur ses musiques de même nom; Les Chercheuses de lune (1973) sur Fantasmes; Jeux de je (1976) sur sa Première Sonate pour violon et piano; Lianes (1977) puis Vivre à deux (1982, sur sa Première Sonate pour violoncelle; D'Or et de plomb sur Chorégraphie 1; toutes pièces de Martine Époque; et 13 : densité harmonique, de Paul Lapointe, sur son Deuxième Quatuor à cordes.

André était véritablement un homme rayonnant. Fautil alors se surprendre si, à l'issue de la célébration de sa cérémonie funéraire, alors que la nef de l'église se retrouvait presque vide et la photo d'André seule sur son chevalet devant le chœur, un rayon de soleil transperçant comme un rayon laser un vitrail côté est vint se poser sur son visage et que, du fond de l'allée, nous avions la ferme impression que c'était André qui irradiait la lumière et illuminait l'au-delà. 